\title{
Pseudonyms and Author Collectives in zbMATH
}

Octavio Paniagua Taboada, Nicolas Roy and Olaf Teschke (all FIZ Karlsruhe, Berlin, Germany)

Writers and authors in general - and also mathematicians - have often used pseudonyms for many different reasons. Sometimes an author wanted to avoid certain political, sexist, ethnic or religious discrimination, or even persecution. Others, perhaps just wanting to keep their private life away from their work, have pursued a career under an alias. Lastly, authors occasionally change their names for practical reasons, ${ }^{1}$ which is, however, beyond the scope of this note. Frequently, the humour of mathematicians has given birth to fictitious persons - often, but not always, the creation of such characters is the idea of a group of authors. Of course, there are also practical reasons for creating collective authors, like the case of larger collaborations whose composition is subject to fluctuations. In this column, we describe some examples and how such information can be retrieved from zbMATH. ${ }^{2}$

\section{Literary pseudonyms}

Perhaps the most famous cases of pseudonyms used by mathematicians have their origin in parallel literary careers. Lewis Carroll (for Charles Lutwidge Dodgson) and Paul Mongré (for Felix Hausdorff) are the most prominent examples, to an extent that even works signed with their pen names have been indexed in the zbMATH database. Here, the zbMATH author profile will automatically display the pseudonyms once the contributions have been acknowledged. The same is true for Helga Bunke, whose literary writings, appearing under her maiden name Helga Königsdorf, arguably outshone her mathematical publications. On the other hand, in an otherwise similar case, the literary pseudonym Irina Grekova of E.S. Wenzel, who also wrote several popular Russian textbooks on probability theory (see, for example, [10]), will not be visible via her indexed publications. The same is true for the pen name John Taine of Eric Temple Bell.

\section{Female mathematicians}

Women's empowerment has been a long and difficult process, wherein they have fought for redefining roles and positions that were previously completely restricted or denied. Science is not an exception and women had to struggle for recognition of their scientific contributions. Sophie Germain (1776-1831) faced the prejudices

\footnotetext{
1 E.g. Rabinowitsch/Rainich, Tajtelbaum/Tarski, Weiss/Fejér and Zaritsky/Zariski.

2 The authors would like to thank the MathOverflow community, Walter Warmuth and Dirk Werner for many valuable hints.
}

of 19th-century society and used the alias M. Le Blanc in her early correspondence with Adrien-Marie Legendre and Carl Friedrich Gauss [7].

\section{War, persecution and political pressure}

In the darkest days of European history, before and during World War II, numerous mathematicians not only used pseudonyms but actually had to change their names permanently in order to hide their Jewish origin after the Nazi party seized power. One remarkable example is André Bloch, who was confined to a psychiatric institution and wrote under the pseudonyms René Binaud and Marcel Segond [3]. Jacques Feldbau was another victim of the Nazi regime, dying in Auschwitz; before being captured, he wrote several works incognito under Jacques Laboureur [4]. Stalinist persecution also led to pseudonyms: both Nikolay S. Koshlyakov and A.I. Lapin could only publish works under the pseudonyms N.S. Sergeev and A.I. Ivanov, in the 1940s and 1950s respectively [5]. Even in the West, Jean van Heijenoort preferred to publish a political article as Jean Vannier in the McCarthy era. While it no longer seems dangerous to make these identities public, there are also recent situations where this is not true. Purportedly, scientists in Iran frequently prefer to use pseudonyms when their work involves colleagues from Israel. For obvious reasons, zbMATH would not make these identities public even if they were known to us.

\section{Other reasons for pseudonyms}

It is quite interesting that there are mathematicians who wrote some articles under their real name and some under an alias (not an author collective). In this category, there is William Sealy Gosset, who wrote several papers under the pen name Student. From these papers came the famous t-test or Student test in statistics [9]. Fields Medallist Heisuke Hironaka once published a paper under the alias of Hej Iss'sa as an homage to a Japanese poet [6]. The mathematician R.P. Boas wrote a very famous article under the pseudonym E.S. Pondiczery; this name was later adopted in the Hewitt-Marczewski-Pondiczery theorem. Apparently, Boas was known for his remarkable sense of humour [1]. Humour also appears to be the origin of pseudonyms like Sally Popkorn (of Harold Simmons) and the names of many collectives (see below). The cheekiness of some authors sometimes leads them to sign their publications with multiple names, like, for example, Hermann Laurent, who published a paper in 1897 under the double name "C.A. Laisant \& É. Lemoine" (two of his colleagues). The famous feline co-author F.D.C. Willard of the physicist and mathematician Jack $\mathrm{H}$. Hetherington is another interesting example [11]. 


\section{Anonymous authors}

Certain mathematicians wanted to be kept anonymous completely. Sometimes, they signed their papers with " $\mathrm{X}$ ", "former student", "a student" or "anonymous". There is also the famous case of Joseph Diez Gergonne, who submitted several of his articles anonymously or under an alias. He subsequently added his name to his own copies, which were later donated to the Sorbonne Library [8].

Actually, you can check the profile "anonymous." (https://zbmath.org/authors/anonymous.) in zbMATH and you will see how many interesting variants were used by different authors:

Anonymous authors (collective author)

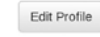

Published as: (Un Bibliophile); Ancien Élève; Ancien élève de Math. spéc.; Anon: Anon; Anonimo; Anorym; Anonyme; Anorymes; Anonymous; Anonymus; Ein Leser, N. N.: Un Abonné: Un Abonne.; Un Correspondant; Un Dilettante; Un ancien éleve.; Un anoryme.; Unbekannt; Ungenannt; Ungenannter, the anorymous referee

Members: Not lientife

Documents Indexed: 125 Pubications since 1826, including 9 Books

Co-Authors 123 single-authored 1 Barisien, E.N.

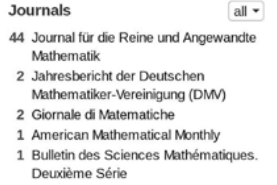

Fields 5 General mathematics $(00-x)$ 4 History and biography (01- $\times x)$ 3 Number theory $(11-x x)$ 2 Field theory and polynomials (12-xx) Deuxième Série

All these variants are collected into this "anonymous" group until further information is available. We invite the reader to read the very interesting discussion on MathOverflow concerning pseudonyms of mathematicians: https://mathoverflow.net/questions/45185/pseudonyms-of-famous-mathematicians.

There, you will also find some very interesting anecdotes (some of them apocryphal) and more pseudonyms.

\section{Author collectives}

Nicolas Bourbaki is arguably the most famous author collective in the mathematics literature. L. Banlieu, in her article [2], states that in the early years of Bourbaki (1934-1935), the following members formed the Bourbaki team: Henri Cartan, Claude Chevalley, Jean Delsarte, Jean Dieudonné, Szolem Mandelbrojt, René de Possel and André Weil. The physicist Jean Coulomb and Charles Ehresmann joined the team later. If you check the profile of the collective author in zbMATH, you can see that 45 members have worked at various points in this collective. Is this all of them? Maybe not - it would not be surprising if we were still missing some names.

Bourbaki is, in fact, the inspiration for other collective authors. Here, we mention the collective Arthur Lancelot Besse, which is a group of mathematicians publishing mainly in differential geometry. Other collectives include the famous John Rainwater, K. Blizzard, R.B. Honor, Peter Ørno, Y.T. Rhineghost, Boto (meaning Bochumer Topologen) von Querenburg and K. M.S. Humak, ${ }^{3}$ which also involved Helga Bunke who was mentioned above. By design, the massive collaborative Polymath projects involve many mathematicians. While resulting achieve-

\footnotetext{
3 Kollektiv Mathematische Statistik: Humboldt-Universität zu Berlin und Akademie der Wissenschaften der DDR.
}

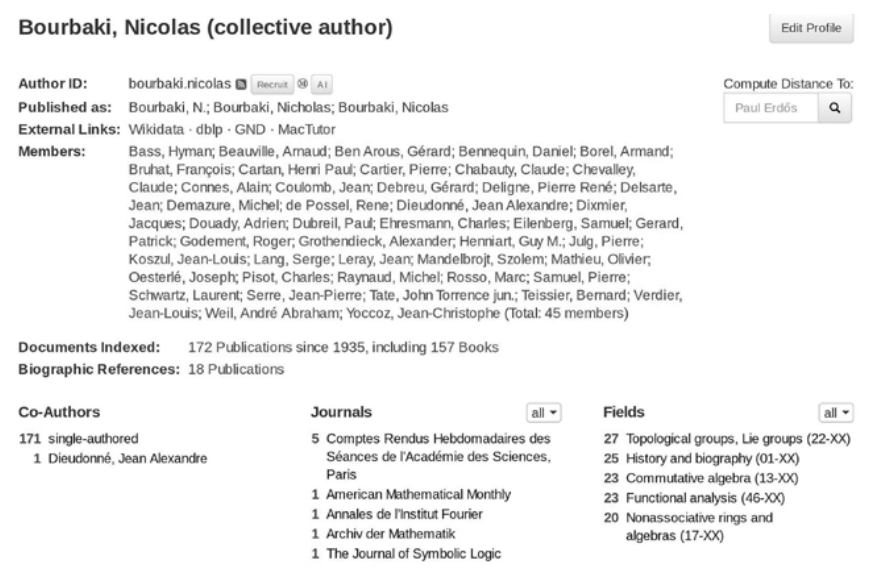

ments have been published only under the name of D.H.J. Polymath, it might make sense to distinguish it in the future by the project number. In any case, it remains challenging to maintain an exhaustive list of members. In recent times, Polymath has produced several deep results on bounded gaps between primes and bounded intervals containing primes.

A list of all collective authors currently identified in zbMATH can be retrieved in the author database via https://zbmath.org/authors/?q=st:o.

We invite our readers to check other collective authors in zbMATH and to send us your feedback on all these topics!

\section{References}

1. Gerald L. Alexanderson; Dale H. Mugler. Lion hunting and other mathematical pursuits: a collection of mathematics, verse, and stories by Ralph P. Boas, Jr. Washington, DC: MAA. xii, 308 p., (1995; Zbl 0854.00001).

2. Liliane Banlieu. Dispelling a myth: Questions and answers about Bourbaki's early work, 1934-1944. In: Chikara, Sasaki (ed.) et al., The intersection of history and mathematics. Papers presented at the history of mathematics symposium, held in Tokyo, Japan, 31 August-1 September 1990. Basel: Birkhäuser. Sci. Networks, Hist. Stud. 15, 241-252, (1994; Zbl 0819.01015).

3. Douglas M. Campbell. Beauty and the beast: The strange case of André Bloch. Math. Intell., 7, No. 4, 36-38, (1985; Zbl 0569.01012).

4. Jean Cerf. Allocution prononcée le 5 juin 1947. Gaz. Math., Soc. Math. Fr., 64, 23-28, 1995.

5. S.S. Demidov, Vopr. Istor. Estestvozn. Tekh. 2001, No. 2, 122-126 (2001; Zbl 0996.01013).

6. Lê Dũng Tráng; Bernard Teissier. On the mathematical work of Professor Heisuke Hironaka. Publ. Res. Inst. Math. Sci. 44, No. 2, 165-177, (2008; Zbl 1144.01312).

7. Mary W. Gray. Sophie Germain (1776-1831). In: Louise S. Grinstein and Paul Campbell, editors, Women of mathematics: A bibliographic sourcebook, 47-55. Greenwood, (2008).

8. C. Henry. Supplément à la bibliographie de Gergonne. Bonc. Bull. 14, 211-218, (1881; JFM 13.0019.01).

9. M.C. Wendel. Pseudonymous fame. Science 351, Issue 6280, 1406, (2016).

10. E.S. Wentzel. Probability theory (first steps). Transl. from the Russian by N. Deineko. Moscow: Mir Publishers (1982;Zbl 0479.60004).

11. Heinrich Zankl. Irrwitziges aus der Wissenschaft: Von Dunkelbirnen und Leuchtkaninchen. Weinheim: Wyley-VCH Verlag (2008).

Photos and CVs of the authors can be found in previous Newsletter issues. 